\title{
Progress on Global Health Goals: Are the Poor Being Left Behind?
}

Adam Wagstaff, Caryn Bredenkamp, and Leander R. Buisman

We examine differential progress on health Millennium Development Goals (MDGs) between the poor and the better off within countries. Our findings are based on an original analysis of 235 DHS and MICS surveys spanning 64 developing countries over the 1990-2011 period. We track five health status indicators and seven intervention indicators from all four health MDGs. In approximately three-quarters of countries, the poorest 40 percent have made faster progress than the richest 60 percent on MDG intervention indicators. On average, relative inequality in these indicators has been falling. However, in terms of MDG outcome indicators, in nearly half of the countries, relative inequality has been growing. Moreover, in approximately one-quarter of the countries, the poorest 40 percent have been slipping backwards in absolute terms on both MDG interventions and outcomes. Despite reductions in most countries, relative inequalities in MDG health indicators are still appreciable, with the poor facing higher risks of malnutrition and death in childhood and lower odds of receiving key health interventions.

With only a few months to go until the December 31, 2015, target date for the attainment of the Millennium Development Goals (MDGs), global and country-specific progress toward the health-related MDGs is being fervently discussed by ministries of health, development partners, civil society organizations, and health advocates. Recent estimates (Go and Quijada 2012; United Nations 2012; World Bank 2013) show that although progress toward most non-health MDG targets is largely on track, progress toward the health MDG targets is not.

Largely absent from the discussion on the health MDGs has been the question raised by Gwatkin (2005) nearly 10 years ago: whether progress within countries has been pro-poor (i.e., faster among the poor and hence inequality reducing) or prorich. ${ }^{1}$ Only three studies have shed light on this question, and, as we show below, these studies reached different conclusions. As a result, it is currently unclear 
whether progress to date on the health MDGs has been pro-poor or pro-rich for both interventions (e.g., immunization) and outcomes (e.g., under-five mortality).

In this paper, we re-analyze this unresolved question using a larger number of MDG indicators, more countries, more survey years, more recent data, and more measures of inequality than previous studies. We find that with the exception of HIV prevalence, where progress has, on average, been markedly pro-rich, progress on the MDG health outcome (health status) indicators has, on average, been neither prorich nor pro-poor. Average rates of progress are similar among the poorest 40 percent and among the richest 60 percent. On average, the concentration index (the measure of relative inequality that we use) neither rose nor fell. A rosier picture emerges for MDG intervention indicators: whether we compare rates of change for the poorest 40 percent and richest 60 percent or consider changes in the concentration index, we find that progress has, on average, been pro-poor.

However, behind these broad-brush findings lie variations around the mean. Not all countries have progressed in an equally pro-poor way. In almost half of countries, (relative) inequality in child malnutrition and child mortality fell, but it also increased in almost half of countries, often quite markedly. We find some geographic concentration of pro-rich progress; in almost all countries in Asia, progress on underweight has been pro-rich, and in much of Africa, inequalities in under-five mortality have been growing. Even on the MDG intervention indicators, we find that a sizable fraction of countries have progressed in a pro-rich fashion. Progress on skilled birth attendance and antenatal care has been pro-rich in 20 percent of countries, and in as much as 25-30 percent of countries, inequalities in immunization have grown. We also find that despite mostly pro-poor progress over time (at least on the intervention indicators), relative inequalities in MDG health indicators persist. The poor face a higher risk of malnutrition and death in childhood, and their odds of receiving key health interventions are appreciably lower.

Although our analysis focuses on the MDG indicators, it has implications for the measurement and monitoring of trends in inequalities in health status and health interventions more generally. Our finding that progress on health interventions has been more pro-poor than progress on health outcomes raises questions about where to focus efforts on monitoring and how to incentivize, financially or otherwise, reaching the poor.

\section{What Did Previous Studies Find about Whether Progress Toward the Health MDGs Has Been Pro-Poor?}

Table 1 indicates, for each of the main four health-related MDGs, the goal, the targets, the official indicators, and the additional core intermediate indicators that 
Table 1. MDG Health Goals, Targets, and Indicators

\begin{tabular}{|c|c|c|c|}
\hline MDG goal & Targets & Official indicators & Additional core intermediate monitoring indicators $\$$ \\
\hline $\begin{array}{l}\text { Goal 1: Eradicate } \\
\text { extreme poverty } \\
\text { and hunger }\end{array}$ & $\begin{array}{l}\text { Halve, between } 1990 \text { and } \\
\text { 2015, the proportion of people } \\
\text { who suffer from hunger }\end{array}$ & $\begin{array}{l}\text { Prevalence of underweight children } \\
\text { under five years of age } \\
\text { Proportion of population below } \\
\text { minimum level of dietary energy } \\
\text { consumption }\end{array}$ & $\begin{array}{l}\text { Percentage of children aged } 6 \text { to } 59 \text { months who received } \\
\text { one dose of vitamin A in the past six months, proportion } \\
\text { of infants under six months who are exclusively breastfed }\end{array}$ \\
\hline $\begin{array}{l}\text { Goal 4: Reduce child } \\
\text { mortality }\end{array}$ & $\begin{array}{l}\text { Reduce by two-thirds, between } \\
1990 \text { and 2015, the under- } \\
\text { five mortality rate }\end{array}$ & $\begin{array}{l}\text { Under-five mortality rate } \\
\text { Infant mortality rate } \\
\text { Measles immunization among children } \\
\text { under one }\end{array}$ & $\begin{array}{l}\text { Proportion of infants under six months who are exclusively } \\
\text { breastfed, proportion of surviving infants who have } \\
\text { received a dose of measles vaccine by their first birthday, } \\
\text { proportion of children with fast or difficult breathing in } \\
\text { the past two weeks who received an appropriate antibiotic, } \\
\text { proportion of children with diarrhea in the past two weeks } \\
\text { who received oral rehydration therapy (ORT), proportion } \\
\text { of children under five who slept under an insecticide- } \\
\text { treated net the previous night (in malarious areas), } \\
\text { proportion of children with fever in the past two weeks } \\
\text { who received an appropriate anti-malarial (in malarious } \\
\text { areas) }\end{array}$ \\
\hline $\begin{array}{l}\text { Goal 5: Improve } \\
\text { maternal health }\end{array}$ & $\begin{array}{l}\text { Reduce by three-quarters, } \\
\text { between } 1990 \text { and } 2015 \text {, the } \\
\text { maternal mortality ratio }\end{array}$ & $\begin{array}{l}\text { Maternal mortality ratio } \\
\text { Proportion of births attended by skilled } \\
\text { health personnel }\end{array}$ & $\begin{array}{l}\text { Contraceptive prevalence rate, percentage of women with } \\
\text { any antenatal care, provision of emergency obstetric care, } \\
\text { syphilis in pregnant women and proportion that are } \\
\text { properly treated, percentage of women receiving antenatal } \\
\text { care who receive at least two to three intermittent } \\
\text { preventive malaria treatments during pregnancy (in } \\
\text { malarious areas) }\end{array}$ \\
\hline
\end{tabular}


Table 1. Continued

\begin{tabular}{|c|c|c|c|}
\hline MDG goal & Targets & Official indicators & Additional core intermediate monitoring indicators ${ }^{\S}$ \\
\hline \multirow[t]{3}{*}{$\begin{array}{l}\text { Goal 6: Combat HIV/ } \\
\text { AIDS, malaria and } \\
\text { other diseases }\end{array}$} & $\begin{array}{l}\text { Have halted by } 2015 \text { and begun } \\
\text { to reverse the spread of HIV/ } \\
\text { AIDS }\end{array}$ & $\begin{array}{l}\text { HIV prevalence among } 15 \text { - to } 24 \text {-year- } \\
\text { old pregnant women } \\
\text { Condom use rate of the contraceptive } \\
\text { prevalence rate } \\
\text { Number of children orphaned by } \\
\text { HIV/AIDS }\end{array}$ & $\begin{array}{l}\text { Percentage of persons using a condom at last higher-risk } \\
\text { sex, percentage of sexually transmitted infection clients } \\
\text { who are appropriately diagnosed and treated according to } \\
\text { guidelines, percentage of HIV-positive women receiving } \\
\text { anti-retroviral treatment during pregnancy to prevent } \\
\text { mother-to-child transmission of HIV }\end{array}$ \\
\hline & $\begin{array}{l}\text { Have halted by } 2015 \text { and begun } \\
\text { to reverse the incidence of } \\
\text { malaria and other major } \\
\text { diseases }\end{array}$ & $\begin{array}{l}\text { Prevalence of and death rate associated } \\
\text { with malaria } \\
\text { Proportion of population in malaria } \\
\text { risk areas using effective malaria } \\
\text { prevention and treatment measures }\end{array}$ & $\begin{array}{l}\text { Percentage of patients with uncomplicated malaria who } \\
\text { received treatment within } 24 \text { hours of onset of symptoms, } \\
\text { percentage of children under five sleeping under } \\
\text { insecticide-treated nets, percentage of pregnant women } \\
\text { sleeping under insecticide-treated nets, percentage of } \\
\text { pregnant women who have taken chemoprophylaxis or } \\
\text { drug treatment for malaria }\end{array}$ \\
\hline & & $\begin{array}{l}\text { Prevalence of and death rates } \\
\text { associated with tuberculosis } \\
\text { Proportion of tuberculosis cases } \\
\text { detected and cured under directly } \\
\text { observed treatment, short-course } \\
\text { (DOTS) }\end{array}$ & $\begin{array}{l}\text { Percentage of estimated new smear-positive tuberculosis } \\
\text { cases that were registered under the DOTS approach }\end{array}$ \\
\hline
\end{tabular}

Source: Wagstaff and Claeson (2004).

Notes: ${ }^{\S}$ Additional core intermediate monitoring indicators are those recommended by a technical consultation between the World Bank and UN technical agencies and are as reported in Table 2.1 of Wagstaff and Claeson (2004). That table also lists optional indicators. 
Table 2. Previous Studies of Differential Progress by Wealth toward the Health MDGs

\begin{tabular}{|c|c|c|c|}
\hline & Moser et al. (2005) & Suzuki et al. (2012) & Victora et al. (2012) \\
\hline Time period & $1990-2001$ & $1995-2007$ & $1990-2007$ \\
\hline No. countries & 22 & 40 & 35 \\
\hline Data source & $\begin{array}{l}\text { Demographic and Health } \\
\text { Survey (DHS) }\end{array}$ & $\begin{array}{l}\text { Demographic and Health } \\
\text { Survey (DHS), Multiple } \\
\text { Indicator Cluster Survey } \\
\text { (MICS) }\end{array}$ & $\begin{array}{l}\text { Demographic and } \\
\text { Health Survey (DHS) }\end{array}$ \\
\hline $\begin{array}{l}\text { No. surveys per } \\
\text { country }\end{array}$ & 2 & 2 & 2 \\
\hline Official indicators & Under-five mortality & $\begin{array}{l}\text { Prevalence of underweight } \\
\text { children under five years of } \\
\text { age } \\
\text { Under-five mortality rate } \\
\text { Infant mortality rate } \\
\text { Measles immunization among } \\
\text { children under one } \\
\text { Proportion of births attended } \\
\text { by skilled health personnel }\end{array}$ & $\begin{array}{l}\text { Skilled birth attendant } \\
\text { Measles immunization }\end{array}$ \\
\hline $\begin{array}{l}\text { Additional core } \\
\text { intermediate } \\
\text { monitoring } \\
\text { indicators }\end{array}$ & None & $\begin{array}{l}\text { Use of insecticide-treated } \\
\text { bednets by under-five children } \\
\text { Proportion of infants under six } \\
\text { months who are exclusively } \\
\text { breastfed } \\
\text { Proportion of children with } \\
\text { diarrhea in the past two weeks } \\
\text { who received oral rehydration } \\
\text { therapy (ORT) } \\
\text { Proportion of children with } \\
\text { fever in the past two weeks } \\
\text { who received an appropriate } \\
\text { anti-malarial (in malarious } \\
\text { areas) } \\
\text { Contraceptive prevalence rate }\end{array}$ & $\begin{array}{l}\text { Use of insecticide- } \\
\text { treated bednets by } \\
\text { under-five children }\end{array}$ \\
\hline Stratifying variable & Wealth index & Wealth index & Wealth index \\
\hline Summary statistic & $\begin{array}{l}\text { Changes in ratio of the } \\
\text { richest } 20 \text { percent to the } \\
\text { poorest } 20 \text { percent }\end{array}$ & $\begin{array}{l}\text { Changes in ratio of the richest } \\
20 \text { percent to the poorest } 20 \\
\text { percent }\end{array}$ & $\begin{array}{l}\text { Changes in } \\
\text { concentration index }\end{array}$ \\
\hline Findings & $\begin{array}{l}\text { An approximately equal } \\
\text { number of countries with } \\
\text { widening and narrowing } \\
\text { inequalities }\end{array}$ & $\begin{array}{l}\text { Pro-poor progress on } \\
\text { underweight } \\
\text { Pro-rich progress on under-five } \\
\text { mortality } \\
\text { Pro-poor progress on most } \\
\text { intervention indicators except } \\
\text { skilled birth attendance }\end{array}$ & $\begin{array}{l}\text { Inequalities have been } \\
\text { falling over time }\end{array}$ \\
\hline
\end{tabular}

Source: Authors' compilation based on listed studies. 
emerged from a technical consultation between the UN technical agencies and the World Bank in 2001.

Table 2 summarizes the three previous studies (Moser et al. 2005; Suzuki et al. 2012; Victora et al. 2012) that shed light on the issue of whether progress toward the health MDGs has been pro-poor at the country level. The studies vary in the time period under analysis and in the number of countries studied. Two use only the Demographic and Health Survey (DHS), whereas one uses both the DHS and the Multiple Indicator Cluster Survey (MICS). One study focuses on only one MDG and one official indicator, another looks at two MDGs and one official indicator of each, and a third looks at three MDGs and six official indicators.

In the absence of consumption data, the preferred measure of household living standards in developing countries (Deaton 1997), all three studies distinguish between poor and better-off households using the 'wealth index' developed by Filmer and Pritchett (2001). Two of the previous three studies address the inequality issue by looking at changes in the ratio of the outcome among the poorest quintile to the outcome among the richest quintile. The other uses the concentration index (Kakwani et al. 1997), analogous to the Gini coefficient except that when considering inequality in, say, underweight, individuals are ranked by the household's score on the wealth index rather than by underweight. Both approaches speak to the issue of relative - rather than absolute - inequality and shed light on whether progress has been pro-poor in a relative sense (in which case relative inequality is said to have fallen).

The findings of the three previous studies are mixed. Examining under-five mortality (U5MR) between 1990 and 2001, Moser et al. (2005) find no clear trend, whereas Suzuki et al. (2012) find that the progress between 1995 and 2007 in the MDG 1, 4, and 5 outcomes was generally pro-rich. On interventions, both Suzuki et al. (2012) and Victora et al. (2012) mostly find pro-poor progress, except for skilled birth attendance (SBA), where Suzuki et al. (2012), but not Victora et al. (2012), find that progress has been pro-rich.

\section{Data and Indicators}

\section{Data}

Data are drawn from the DHS and the MICS surveys. These global household survey programs are the only regular source of comparable household-level data from which the health MDG monitoring indicators can be constructed. We analyzed the raw data from 164 DHS surveys and 71 MICS surveys covering a total of 91 countries between 1990 and 2011. After eliminating countries with only one period of data and one dataset with some implausible values, we were left with 64 countries 
Table 3. Details of the Datasets Used in the Current Study

\begin{tabular}{llccccc}
\hline & & & & \multicolumn{3}{c}{ Surveys per country } \\
\cline { 5 - 7 } MDG & \multicolumn{1}{c}{ Indicator } & No. countries & No. surveys & Average & Minimum & Maximum \\
\hline 1 & Stunting & 53 & 156 & 2.9 & 2 & 5 \\
1 & Underweight & 54 & 158 & 2.9 & 2 & 5 \\
4 & IMR & 41 & 126 & 3.1 & 2 & 5 \\
4 & U5MR & 41 & 125 & 3.0 & 2 & 5 \\
4 & Full immunization & 60 & 178 & 3.0 & 2 & 6 \\
4 & Measles immunization & 63 & 188 & 3.0 & 2 & 6 \\
5 & ANC4+ & 41 & 127 & 3.1 & 2 & 5 \\
5 & SBA & 41 & 127 & 3.1 & 2 & 5 \\
5 & Contraceptive prevalence & 38 & 87 & 2.3 & 2 & 4 \\
6 & Condom use in risky intercourse & 15 & 32 & 2.1 & 2 & 3 \\
6 & HIV prevalence & 9 & 18 & 2.0 & 2 & 2 \\
6 & Malaria nets (children) & 23 & 54 & 2.3 & 2 & 3 \\
& Average & 40 & 115 & 2.7 & 2 & 4.5 \\
\hline
\end{tabular}

Source: Authors' calculations from original DHS and MICS datasets.

Notes: IMR: Infant mortality rates; U5MR: Under-five mortality rates; ANC4+: Antenatal care visits (4+); SBA: Skilled birth attendance.

with at least two periods of data. Depending on the MDG indicator (see below for selection criteria and definitions), we have data for between 9 and 63 countries, with an average of 40 countries per indicator (table 3). There are some indicators with up to six surveys per country, but the average is 2.7 .

Thus, we cover more countries than previous studies: 64 countries compared with the 22 analyzed by Moser et al. (2005), the 40 analyzed by Suzuki et al. (2012), and the 35 analyzed by Victora et al. (2012). Unlike previous studies whose trends have been estimated from only two surveys per country per indicator, ours are estimated from several surveys per country per indicator, for an average of 2.7.

\section{Indicators}

Table 4 shows the MDG indicators and the definitions used. Our list includes five health status indicators (stunting, underweight, infant mortality, under-five mortality, and HIV prevalence); the rest are intervention indicators. Our aim was to include as many of the official indicators as possible for each MDG. ${ }^{2}$ We have included in our analysis five additional indicators that are almost always used in MDG monitoring exercises, drawn from the additional core intermediate indicators listed in table 1 . Specifically, we include the prevalence of stunted children (MDG1), the percentage of children aged one who have been fully immunized (MDG4), ${ }^{3}$ the percentage of 
Table 4. MDG Indicators Used in the Current Study

\begin{tabular}{|c|c|c|}
\hline MDG goal & Indicator & Definition \\
\hline \multirow[t]{2}{*}{$\begin{array}{l}\text { Goal 1: Eradicate extreme } \\
\text { poverty and hunger }\end{array}$} & Underweight & $\begin{array}{l}\text { Percentage of children with a weight-for-age } \\
\text { z-score }<-2 \text { standard deviations from the } \\
\text { reference median } \$\end{array}$ \\
\hline & Stunting & $\begin{array}{l}\text { Percentage of children with a height-for-age } \\
\text { z-score }<-2 \text { standard deviations from the } \\
\text { reference median } \\
\S\end{array}$ \\
\hline \multirow[t]{5}{*}{$\begin{array}{l}\text { Goal 4: Reduce child } \\
\text { mortality }\end{array}$} & $\begin{array}{l}\text { Infant mortality rate } \\
\text { (IMR) }\end{array}$ & $\begin{array}{l}\text { Number of deaths among children under } \\
12 \text { months of age per } 1,000 \text { live births } \$\end{array}$ \\
\hline & $\begin{array}{l}\text { Under-five mortality rate } \\
\text { (U5MR) }\end{array}$ & $\begin{array}{l}\text { Number of deaths among children under } 5 \text { years of } \\
\text { age per } 1,000 \text { live births } \$\end{array}$ \\
\hline & Measles immunization & $\begin{array}{l}\text { Percentage of children aged } 12 \text { to } 23 \text { months who } \\
\text { received measles either verified by card or by } \\
\text { recall of respondent }\end{array}$ \\
\hline & Full immunization & $\begin{array}{l}\text { Percentage of children aged } 12 \text { to } 23 \text { months who } \\
\text { received BCG, measles, and three doses of polio } \\
\text { and DPT, either verified by card or by recall of } \\
\text { respondent }\end{array}$ \\
\hline & Malaria nets (children) & $\begin{array}{l}\text { Percentage of children under } 5 \text { sleeping under an } \\
\text { (ever) insecticide-treated bednet the previous } \\
\text { night }\end{array}$ \\
\hline \multirow[t]{3}{*}{$\begin{array}{l}\text { Goal 5: Improve maternal } \\
\text { health }\end{array}$} & $\begin{array}{l}\text { Skilled birth attendant } \\
\text { (SBA) }\end{array}$ & $\begin{array}{l}\text { Percentage of births to mothers aged } 15 \text { to } 49 \text { that } \\
\text { were attended by skilled health attendant (SBA) }\end{array}$ \\
\hline & $\begin{array}{l}\text { Antenatal care visits }-4 \\
\text { or more }(\mathrm{ANC} 4+)\end{array}$ & $\begin{array}{l}\text { Percentage of mothers aged } 15 \text { to } 49 \text { who received } \\
\text { at least four antenatal care (ANC4+) visits from } \\
\text { any skilled personnel (as defined in the country's } \\
\text { DHS or MICS) }\end{array}$ \\
\hline & Contraceptive prevalence & $\begin{array}{l}\text { Percentage of women aged } 15 \text { to } 49 \text { who currently } \\
\text { use a modern method of contraception }\end{array}$ \\
\hline \multirow{3}{*}{$\begin{array}{l}\text { Goal 6: Combat HIV/AIDS, } \\
\text { malaria and other } \\
\text { diseases }\end{array}$} & HIV prevalence & $\begin{array}{l}\text { Percentage of adults aged } 15 \text { to } 49 \text { testing positive } \\
\text { for HIV } 1 \text { or } 2\end{array}$ \\
\hline & $\begin{array}{l}\text { Condom use in risky } \\
\text { intercourse }\end{array}$ & $\begin{array}{l}\text { Percentage of women aged } 15 \text { to } 49 \text { who had more } \\
\text { than one partner in the past year and used a } \\
\text { condom during last sexual intercourse }\end{array}$ \\
\hline & Malaria nets (children) & $\begin{array}{l}\text { Percentage of children under } 5 \text { sleeping under an } \\
\text { (ever) insecticide-treated bednet the previous } \\
\text { night }\end{array}$ \\
\hline
\end{tabular}

Notes: ${ }^{\S}$ WHO 2006 child growth standards used to calculate z-score. ${ }^{\$}$ Mortality rate calculated using the true cohort life table approach. The DHS reports use the synthetic cohort life table approach.

children in malaria-endemic countries who sleep under an insecticide-treated bednet (MDG4 and MDG6), antenatal visit coverage (MDG5), and whether a condom was used during sexual intercourse with a high-risk partner (MDG6). 
Our study thus extends the range of indicators well beyond those previously studied. Unlike Moser et al. (2005), who focused on MDG outcomes (in fact, only one outcome: under-five mortality) and Victora et al. (2012), who focused on MDG interventions, but similar to Suzuki et al. (2012), we analyze data on both MDG outcomes and MDG interventions. Although Suzuki et al. (2012) analyze more indicators than we do, we analyze more MDG indicators. ${ }^{4}$

\section{Stratification by 'Wealth'}

As in previous studies, we stratify households by Filmer and Pritchett's 'wealth' index. $^{5}$ Where available, we use the wealth index variable that is included in the public release of most DHS or MICS datasets. For a handful of MICS surveys, we had to construct the wealth index ourselves. In each case, when using wealth quintiles, we sorted households into quintiles. Individuals then acquire the quintile of their household, so that in an analysis of, for example, child mortality, the "poorest quintile' may account for more than 20 percent of children in the sample.

\section{Results}

We ask first how well countries as a whole are progressing on the MDG indicators and display our results in such a way as to show the full variation across countries and across indicators in rates of progress. We then examine progress among the poorer wealth quintiles, ${ }^{6}$ both in absolute terms and relative to the rest of the population. Finally, we explore more systematically how wealth-related inequalities in the MDG indicators have changed over time. Table 5 integrates the key summary statistics that emerge from our analysis. Figures $1-6$ provide much more detail and highlight the heterogeneity across developing countries.

\section{How Fast Is the Developing World Progressing toward the Health MDGs?}

Figure 1 shows the average annual growth rates for all countries (ranked in ascending order of their growth rate) on each of our MDG indicators; see also columns 1 and 2 of table $5 . .^{7}$ The growth curves allow us to see at a glance the median annual growth rate for each indicator and the fraction of countries experiencing negative and positive growth. For the health status (intervention) indicators, progress entails a country having a negative (positive) value of average annual growth in table 5 and being below (above) the zero line on the $y$-axis in figure 1 . Thus, for the health status (intervention) indicators, the further below (above) the horizontal axis the growth curve is in figure 1 , the swifter progress has been. 
Table 5. Key Summary Statistics on Differential Progress by Wealth toward the Health MDGs

\begin{tabular}{|c|c|c|c|c|c|c|c|c|c|c|c|c|c|}
\hline \multirow[b]{2}{*}{ Indicator } & \multicolumn{5}{|c|}{ Annual growth } & \multicolumn{4}{|c|}{ Relative inequality } & \multicolumn{4}{|c|}{ Absolute inequality } \\
\hline & $\begin{array}{l}\text { Median } \\
\text { growth } \\
\text { rate pop }\end{array}$ & $\begin{array}{c}\% \text { countries } \\
\text { where pop } \\
\text { mean } \\
\text { improved }\end{array}$ & $\begin{array}{c}\text { Median } \\
\text { growth } \\
\text { rate } \\
\text { poorest } \\
40 \%\end{array}$ & $\begin{array}{c}\% \text { countries } \\
\text { where mean } \\
\text { for poorest } \\
40 \% \\
\text { improved }\end{array}$ & $\begin{array}{l}\text { Median } \\
\text { excess } \\
\text { growth of } \\
\text { poorest } \\
40 \%\end{array}$ & $\begin{array}{c}\text { Median } \\
\text { initial } \\
\mathrm{CI}^{\S}\end{array}$ & $\begin{array}{c}\% \\
\text { countries } \\
\text { with fall in } \\
\mathrm{CI}^{\S}\end{array}$ & $\begin{array}{c}\text { Median } \\
\text { change in } \\
C I^{\S} \text { p.a. }\end{array}$ & $\begin{array}{l}\text { as \% of } \\
\text { median } \\
\text { initial } C^{\S} \\
\text { (absolute } \\
\text { value) }\end{array}$ & $\begin{array}{c}\text { Median } \\
\text { initial } \\
\text { absolute } \\
C I^{\S}\end{array}$ & $\begin{array}{c}\text { \% countries } \\
\text { with fall in } \\
\text { absolute } \\
\mathrm{CI}^{\S}\end{array}$ & $\begin{array}{c}\text { Median } \\
\text { change in } \\
\text { absolute } \\
C I^{\S} \text { p.a. }\end{array}$ & $\begin{array}{c}\text { as \% of } \\
\text { median } \\
\text { initial } \\
\text { absolute } C I^{\S} \\
\text { (absolute } \\
\text { value) }\end{array}$ \\
\hline Stunting & -0.0084 & 64 & -0.0087 & 64 & 0.0023 & -0.1035 & 58 & -0.0009 & 0.8 & -0.0406 & 45 & 0.0001 & 0.3 \\
\hline Underweight & -0.0269 & 80 & -0.0239 & 74 & 0.0064 & -0.1345 & 56 & -0.0012 & 0.9 & -0.0246 & 43 & 0.0004 & 1.8 \\
\hline IMR & -0.0281 & 93 & -0.0283 & 93 & -0.0004 & -0.1039 & 49 & 0.0010 & 0.9 & -0.0080 & 34 & 0.0003 & 3.4 \\
\hline U5MR & -0.0307 & 88 & -0.0328 & 90 & 0.0019 & -0.1209 & 61 & -0.0009 & 0.7 & -0.0143 & 34 & 0.0003 & 2.1 \\
\hline $\begin{array}{l}\text { Full } \\
\text { immunization }\end{array}$ & 0.0242 & 73 & 0.0295 & 72 & 0.0105 & 0.0934 & 68 & -0.0040 & 4.2 & 0.0419 & 58 & -0.0008 & 1.9 \\
\hline Measles & 0.0169 & 78 & 0.0217 & 78 & 0.0091 & 0.0655 & 75 & -0.0025 & 3.8 & 0.0386 & 73 & -0.0012 & 3.1 \\
\hline ANC4+ & 0.0310 & 78 & 0.0445 & 78 & 0.0164 & 0.2001 & 78 & -0.0049 & 2.4 & 0.0571 & 44 & 0.0003 & 0.6 \\
\hline SBA & 0.0183 & 83 & 0.0277 & 80 & 0.0130 & 0.2807 & 73 & -0.0043 & 1.5 & 0.1080 & 49 & 0.0004 & 0.3 \\
\hline Contraception & -0.0143 & 41 & 0.0065 & 50 & -0.0009 & 0.0691 & 53 & -0.0015 & 2.2 & 0.0097 & 53 & -0.0005 & 5.6 \\
\hline HIV prevalence & -0.0101 & 67 & -0.0026 & 56 & 0.0198 & 0.1526 & 67 & -0.0035 & 2.3 & 0.0066 & 89 & -0.0004 & 5.4 \\
\hline HIV condom & 0.0740 & 93 & 0.1095 & 100 & 0.0412 & 0.2446 & 93 & -0.0113 & 4.6 & 0.0625 & 57 & -0.0002 & 0.4 \\
\hline $\begin{array}{l}\text { Malaria-net } \\
\text { children }\end{array}$ & 0.1691 & 78 & 0.3353 & 74 & 0.0480 & 0.2950 & 65 & -0.0304 & 10.3 & 0.0171 & 52 & -0.0001 & 0.8 \\
\hline Av. health status & -0.0208 & 78 & -0.0193 & 75 & 0.0060 & -0.0620 & 58 & -0.0011 & 1.1 & -0.0162 & 49 & 0.0002 & 2.6 \\
\hline Av. interventions & 0.0456 & 75 & 0.0821 & 76 & 0.0196 & 0.1783 & 72 & -0.0084 & 4.2 & 0.0478 & 55 & -0.0003 & 1.8 \\
\hline
\end{tabular}

Source: Authors' calculations from original DHS and MICS datasets.

Notes: ${ }^{\S} \mathrm{CI}$ is the concentration index - see text for definition. 

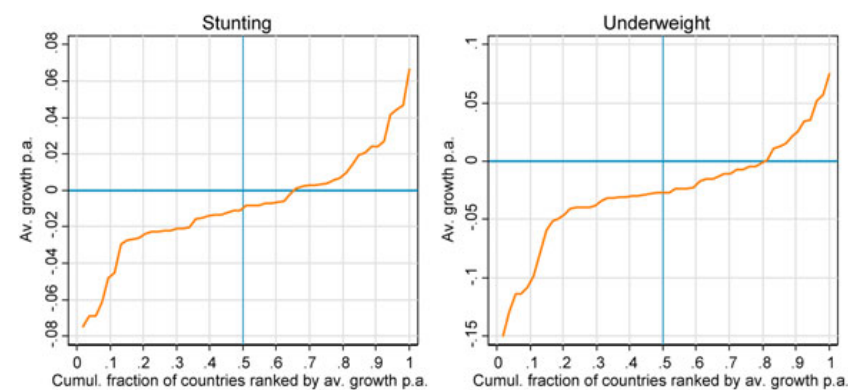

Full immunization

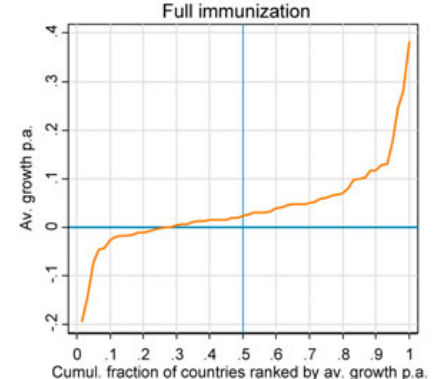

Contraception

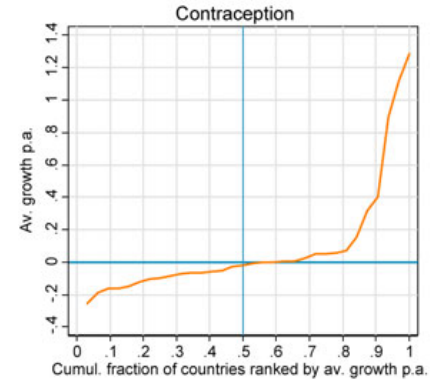

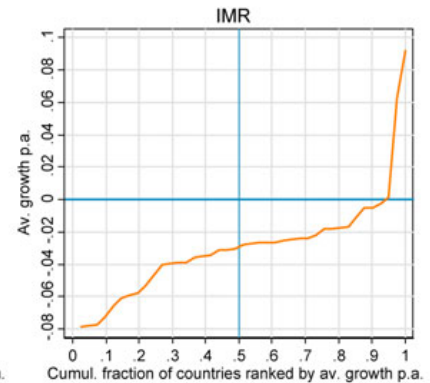

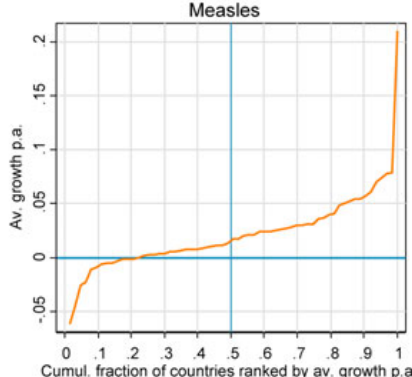

HIV-prevalence

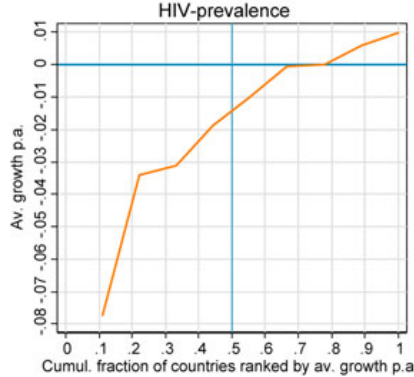

IMR

ANC4+
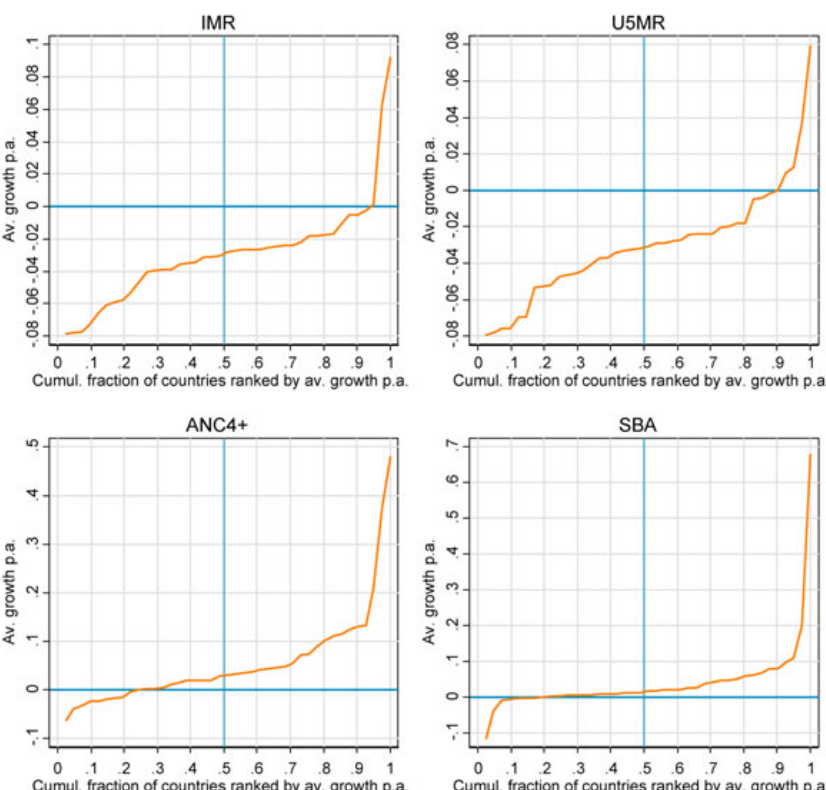

HIV-condom

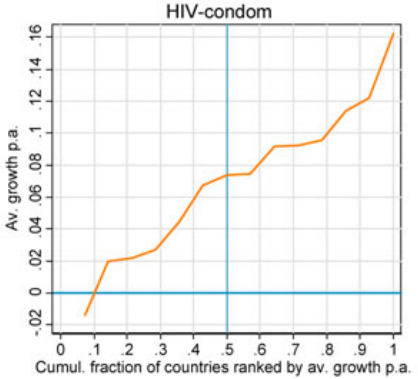

SBA

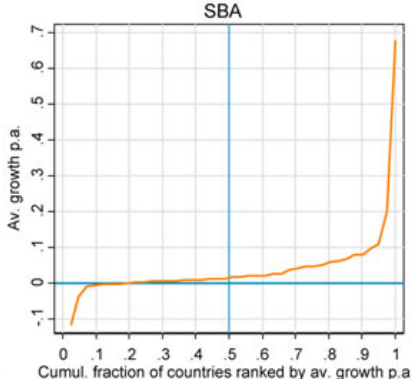

Malaria-net children

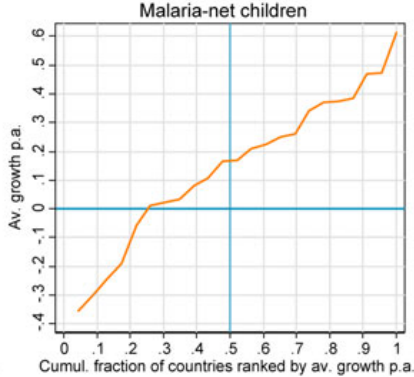

Notes: The annual growth is as a fraction, so, e.g., 0.02 means $2 \%$ annual growth. 
On all indicators except contraception, the majority of countries have made progress. For example, reading across the zero line on the y-axis in the stunting chart, we see that in approximately 65 percent of countries the prevalence of stunting has fallen; for underweight, the figure is 80 percent. All but 22 percent of countries have seen increases in antenatal care coverage. Reading along the median line on the $\mathrm{x}$-axis in the infant mortality rate (IMR) chart, we see that the median annual rate of reduction of IMR is approximately 0.03, or three percent; the median annual rate of increase in measles immunization is approximately two percent.

Several results shown in figure 1 are worth underscoring. First, despite progress for the developing world as a whole, not all countries have made progress toward the MDGs. For some MDGs, the fraction that has not made progress is very high. More than half of countries have seen no progress in contraceptive prevalence, onequarter of countries have not recorded increases in immunization coverage, and one-fifth of countries have not made progress in reducing underweight, with the figure for stunting as high as one-third. Moreover, it is not only a question of some countries not making progress; there are countries that are actually going backwards. In some cases, such as contraception, the countries that are going backwards are doing so fairly slowly; in others, such as infant- and under-five mortality, immunization, and malaria nets, the rates of negative progress are quite high.

A second noteworthy finding illustrated in figure 1 is the variation across indicators in the amount of progress made. The conclusion we draw from this variation, however, depends on whether we look at median rates of growth or the fraction of countries making progress. For example, the median country recorded roughly similar rates of reduction for underweight, IMR and U5MR. However, 93 percent of countries saw progress on IMR, whereas only 80 percent saw such progress on underweight. Overall, progress has been greater for child mortality (Goal 4) than for malnutrition (Goal 1) and maternal health (Goal 5).

A final point to note is that the evenness with which progress is spread across countries varies by indicator. The growth in measles immunization is very flat; very few countries record an exceptionally high growth rate, and none achieved a growth rate of more than 20 percent. The skilled birth attendance (SBA) curve is also fairly flat, but it has a steeper and more extended right tail; approximately five percent of countries averaged growth in excess of 10 percent, some recording growth rates substantially higher than 10 percent. The malaria net growth curve shows much more variation in the spread of growth rates across countries.

\section{How Fast Are the Poor Progressing toward the Health MDGs?}

Figure 2 shows the growth curves for the poorest 40 percent and the richest 60 percent within each country; see also columns 3 and 4 of table 5 . The first conclusion is that for all MDG indicators except contraception, the poorest 40 percent 
Figure 2. Progress toward the Health MDGs among the Poorest 40 Percent and Richest 60 Percent
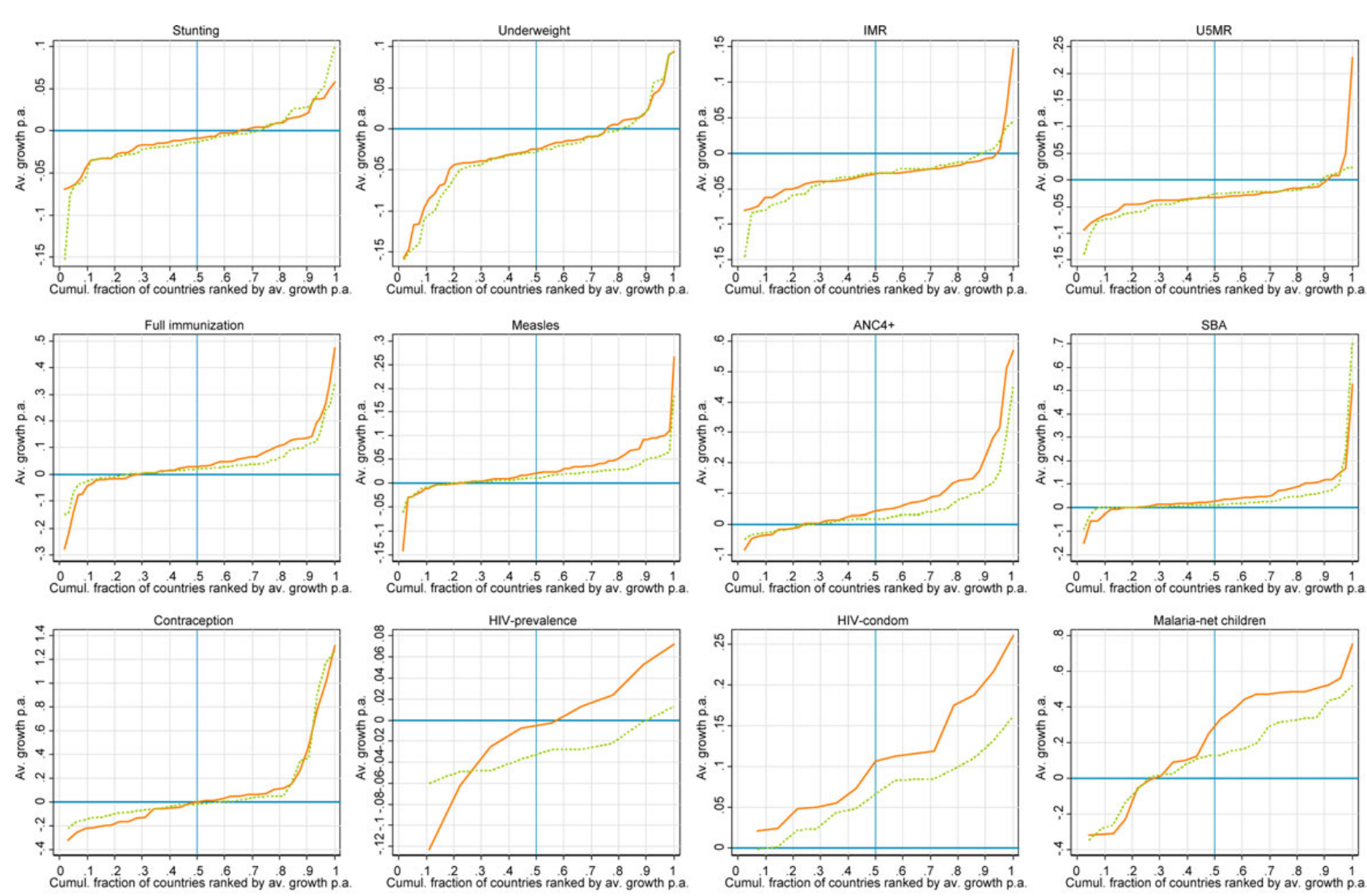
have made progress, whether we measure this in terms of the median growth rate or the fraction of countries in which progress among the poorest 40 percent has occurred. We also see similar broad patterns in the data of the poorest 40 percent and the data for the population as a whole: negative progress among some countries, variations across indicators in the speed of progress, and small pockets of rapid progress on some indicators.

Although the poorest 40 percent have, broadly speaking, shared in the progress toward the health MDGs of the population as a whole, figure 2 reveals some differences in the speed of progress between the poorest 40 percent and richest 60 percent. The degree to which progress has been pro-poor or pro-rich is also shown in figure 3 (and column 5 of table 5), which shows how countries vary in excess growth among the poorest 40 percent (i.e., the excess of the growth rate among the poorest 40 percent over the growth rate among the richest 60 percent). For an intervention indicator, such as immunization, positive excess growth among the poorest 40 percent means faster progress among the poor (i.e., pro-poor progress). For health status indicators, such as underweight and mortality, the opposite is the case; positive excess growth among the poorest 40 percent means pro-rich progress.

On the MDG outcomes, the picture varies somewhat by indicator. For HIV prevalence, progress has been markedly pro-rich. The median rate of reduction for the richest 60 percent was almost three percentage points higher than that for the poorest 40 percent. Although 90 percent of countries saw a reduction in HIV prevalence among the richest 60 percent, only approximately 55 percent of countries saw a reduction in HIV prevalence among the poorest 40 percent. Figure 3 shows that in the case of HIV prevalence, excess (negative) growth among the poorest 40 percent was recorded in only approximately 35 percent of countries.

By contrast, no striking differences in progress between the poor and the better off emerge for malnutrition and child mortality. The growth curves for the poorest 40 percent and the richest 60 percent are close to one another and actually intersect several times, and the excess growth curves in figure 3 all intersect the median line on the $\mathrm{x}$-axis around zero on the y-axis. For both malnutrition indicators, the median rate of reduction among the richest 60 percent is very slightly larger than the median rate among the poorest 40 percent, and the fraction of countries where the richest 60 percent saw reductions in malnutrition is very slightly higher than the fraction of countries where the poorest 40 percent saw reductions. Figure 3 shows that for malnutrition, the fraction of countries that saw negative excess (i.e., pro-poor) growth among the poorest 40 percent is only slightly less than 50 percent, and the median excess growth rate is almost zero. On the excess growth measure, progress on child mortality emerges as neither pro-poor nor pro-rich.

On MDG intervention indicators, a distinctly pro-poor picture emerges. In figure 2, for all indicators except contraception, the growth curve for the poorest 40 percent lies above that for the richest 60 percent. Whether we consider the difference in median 
Figure 3. Incidence of Excess Growth among the Poorest 40 Percent on Health MDG Indicators
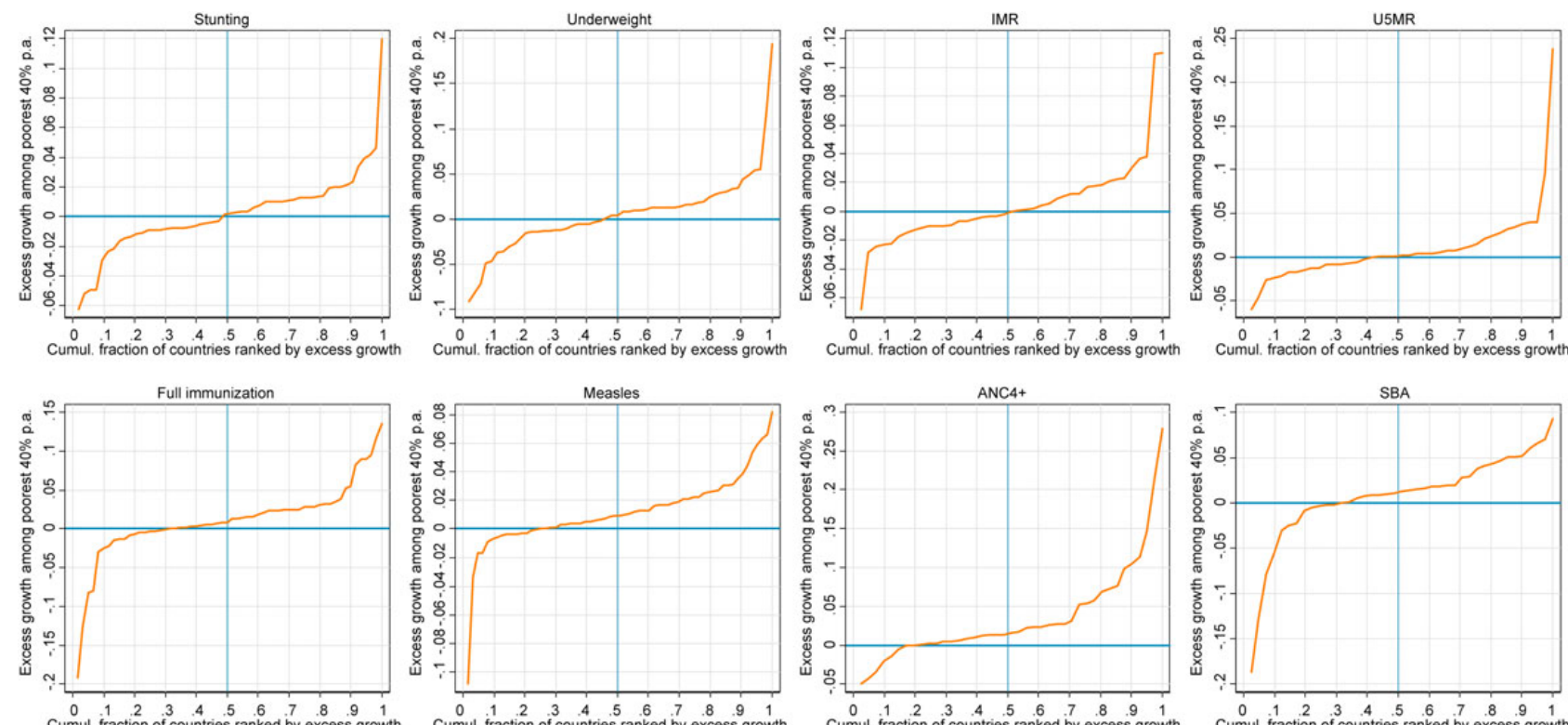

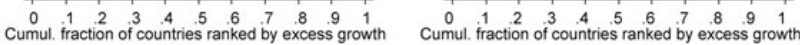
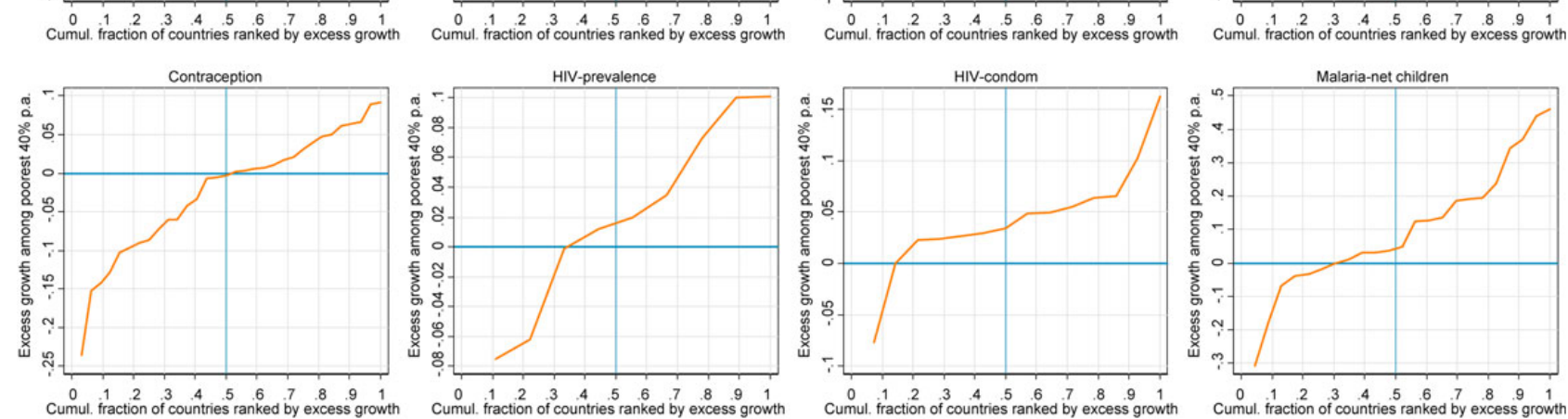

$\stackrel{G}{G} \quad$ Source: Authors' calculations from original DHS and MICS datasets.

Notes: The annual growth is as a fraction, so, e.g., 0.02 means $2 \%$ annual growth. 
growth rates or the difference in the fraction of countries recording progress, we see a pro-poor result. We obtain the same pro-poor picture for MDG intervention indicators in figure 3, where all curves except that for contraception intersect the zero line on the $\mathrm{y}$-axis to the left of the median line on the $\mathrm{x}$-axis. Thus, whether we look at the median rate of excess growth among the poorest 40 percent or at the fraction of countries where there is positive excess growth among the poorest 40 percent, we see the same pro-poor pattern emerges. Using the latter indicator of pro-poorness, figure 3 suggests that progress has been especially pro-poor for antenatal care and condom use, whereas progress in the use of contraception has been neither pro-poor nor pro-rich.

Figure 3 points to large differences across countries in the degree to which progress toward the health MDGs has been pro-poor. For example, while on average progress has been broadly similar for the poorest 40 percent and the richest 60 percent for malnutrition and child mortality, there are some countries (to the left of each graph in figure 3) where progress has been dramatically pro-poor (i.e. growth rates have been more negative for the poorest 40 percent than for the richest 60 percent) but also some countries (to the right of each graph in figure 3) where progress has been markedly pro-rich (i.e. growth rates have been less negative for the poorest 40 percent). Likewise, while, on average, progress on intervention indicators has been pro-poor, figure 3 shows that in plenty of countries, progress has been slower for the poorest 40 percent than for the richest 60 percent.

When we examine geographic patterns, we find that for most indicators, most continents have a mixed picture: some countries have achieved pro-poor progress, but not all. This is less true of Asia and the Americas; for antenatal care and skilled birth attendance, for example, almost all countries in these regions have achieved pro-poor progress. By contrast, in almost all countries in Asia, progress on underweight has been pro-rich. More detailed information on geographic patterns was presented by Wagstaff et al. (2014, Figure 4).

To what extent is overall pro-poor progress attributable to some countries improving systematically across all MDG indicators? Treating each country-indicator combination as an observation and defining the outcome as whether the country recorded excess growth among the poorest 40 percent for that indicator, we performed a twoway analysis of variance. The 12 indicator and 64 country codes were entered as independent variables. We find that two-thirds of the explained variance was attributable to variation across countries, holding indicators constant. In other words, twothirds of the explained variation can be explained by some countries systematically doing better than others in achieving pro-poor progress across all indicators.

\section{How are Wealth-Related Inequalities in the Health MDGs Changing?}

Faster rates of improvement among the poorer wealth groups imply a reduction in wealth-related inequalities in the MDG health indicators. Figures 2 and 3 are thus 
Figure 4. Trends in the Ratio of the Poorest Quintile's MDG Indicator Value to the Richest Quintile's Value
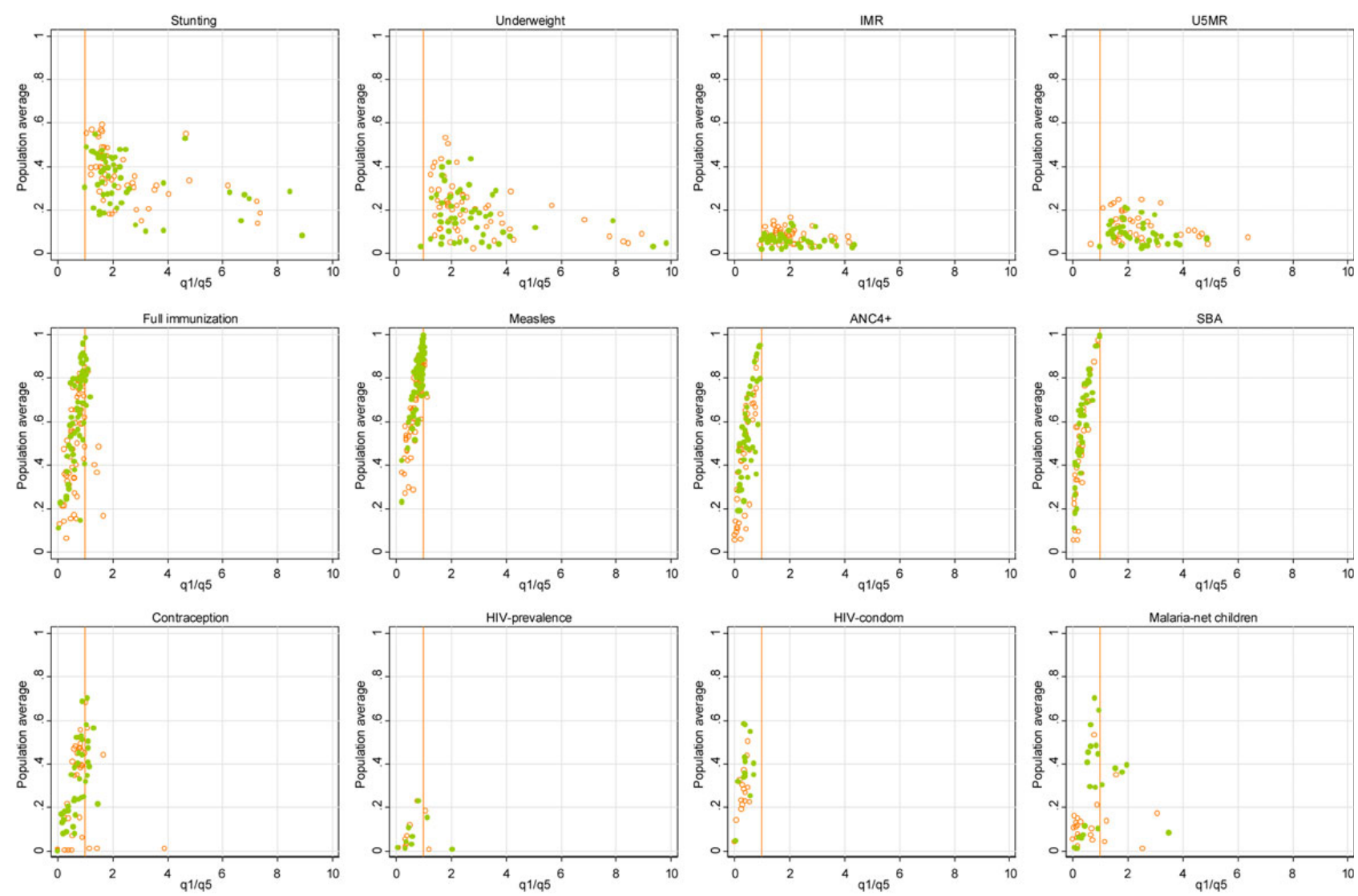

悹

Source: Authors' calculations from original DHS and MICS datasets.

Notes: The population rate is as a fraction, so, e.g., 0.2 means a population average of $20 \%$. This is true also for IMR and U5MR, which are typically expressed per 1,000 . 
suggestive of inequality reduction for the intervention indicators and of little change in inequality for the outcome indicators. However, the charts do not provide a definitive answer on inequality trends. It could be argued that splitting the population into two at the 40 percent mark is a somewhat arbitrary way of tracking inequality. Moreover, the charts do not indicate by how much inequality has been reduced or the amount of inequality remaining at the time of the latest survey. Finally, pro-poor progress - in the sense of faster growth among the poor - implies a reduction in relative inequality but not necessarily in absolute inequality. If the poor start behind the better off, as they do on MDG intervention indicators, they will see a larger absolute increase only if their increase is considerably larger in percentage terms.

A simple - and very incomplete - relative inequality measure is the ratio of the poorest quintile's value to that of the richest quintile. Figure 4 shows this measure for the earliest survey in each country and the latest survey. A more complete measure of wealth-related health status and health intervention inequality is the concentration index (Kakwani et al. 1997). A positive value indicates that the better off, on average, have higher values of the outcome variable (good in the case of an intervention, bad in the case of a negative health status indicator such as malnutrition or mortality), whereas a negative value indicates that they have, on average, lower values (bad in the case of an intervention, good in the case of an indicator such as malnutrition or mortality). With a binary outcome, such as the variables used in this paper, the bounds of the concentration index are $\mu-1$ and $1-\mu$, where $\mu$ is the mean of the outcome variable (Wagstaff 2005). Thus, as the mean increases, the range of possible values shrinks, tending to zero as the mean goes to one. Figure 5 shows the population mean and the concentration index for the earliest and latest surveys for all countries for all MDG indicators; see also column 6 of table $5 .^{8}$

Four points are worth noting in figures 4 and 5 . First, reinforcing the findings of earlier studies, we find pro-rich inequalities on all but one indicator: the poor, on average, have higher rates than the better off on all MDG health status indicators except HIV and lower rates on the MDG intervention indicators. Second, for the intervention indicators, we see the ratios in figure 4 moving closer to one and the concentration indices in figure 5 approaching zero as the population average moves closer to one. All of the charts in figure 5 have a somewhat half-arrowhead appearance, reflecting the fact that the bounds shrink as the population mean rises toward one and that inequality is pro-rich almost everywhere (so that we see only the left or right of the arrowhead). Third, in the case of the intervention indicators, the markers in both charts seem to be rising over time (indicating that population averages are improving) and closing in on the vertical line on the x-axis (indicating that inequalities are falling). For the malnutrition and child mortality indicators, we see the markers falling over time but no clear pattern in terms of inequality. We will return to this in a moment. Fourth, inequalities favoring the better off are still very much in evidence even in the latest round of surveys. 

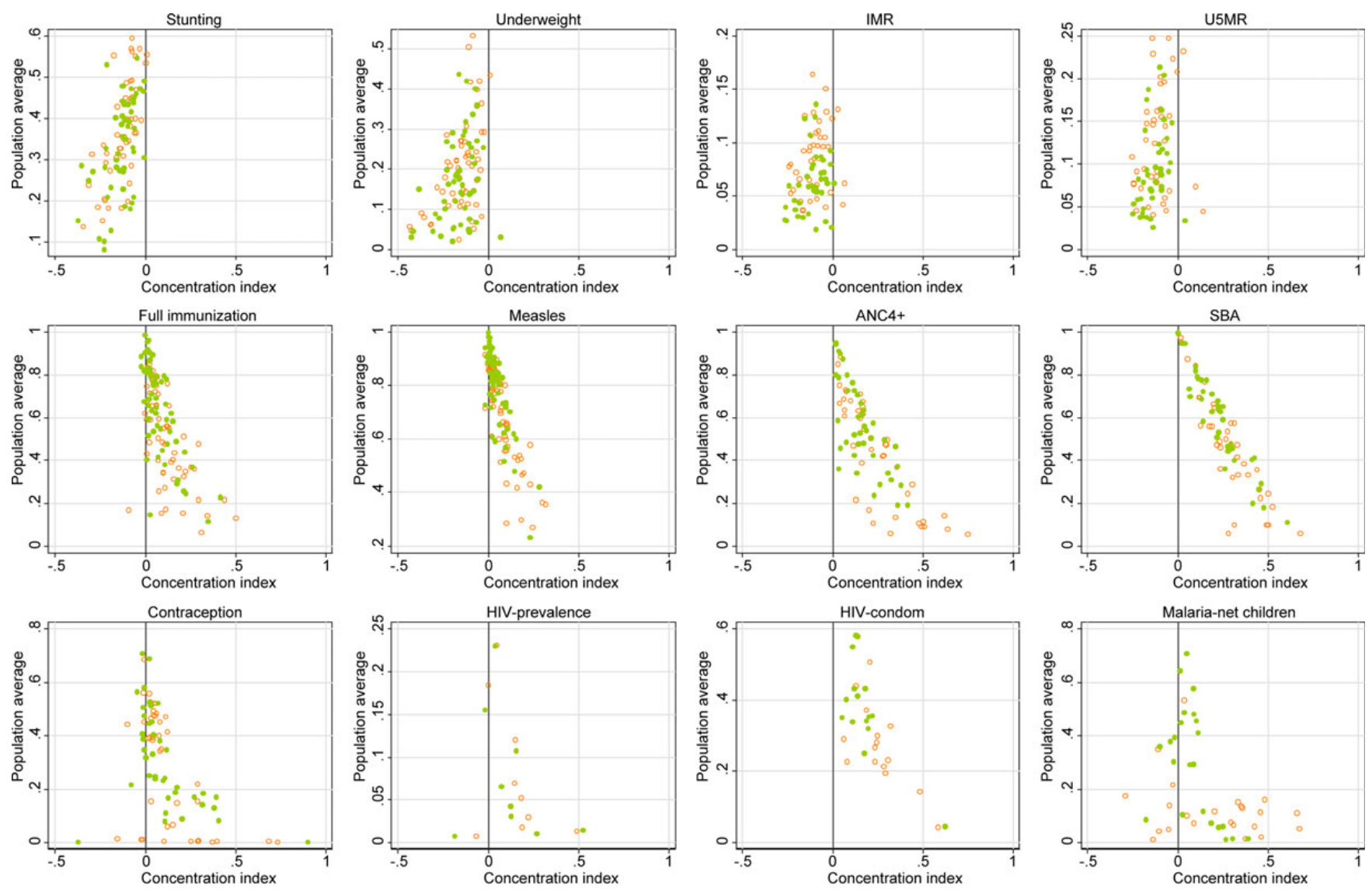

Earliest survey

Latest survey

Source: Authors' calculations from original DHS and MICS datasets.

Notes: The population rate is as a fraction, so, e.g., 0.2 means a population average of 20\%. This is true also for IMR and U5MR, which are typically expressed per 1,000. 
The analogue of the concentration index for the absolute inequality measurement is the absolute concentration index, equal to the mean multiplied by the standard concentration index. ${ }^{9}$ A positive value indicates higher values, on average, among the better off, and a negative value indicates higher values, on average, among the less well off. In the case of a binary outcome, the bounds of the absolute concentration index start at zero when the population mean is zero, grow as the mean rises above zero reaching minimum and maximum values of -0.25 and +0.25 as the mean reaches one half. As the population mean rises further, the bounds shrink, reaching zero again as the mean reaches one. ${ }^{10}$

When we look at absolute inequality (see column 10 of table 5 and figure 7 in Wagstaff et al. (2014)), there are five findings that are worth highlighting. First, absolute inequality also favors the better off. Second, as the population mean rises, absolute inequality does not always decrease; instead, there is a sign - especially visible for the ANC and SBA indicators - of inequalities growing as the population mean increases before diminishing. This is consistent with the bounds of the absolute concentration index having a rotated ellipse shape with minima and maxima of -0.25 and +0.25 . Third, the smaller bounds of the absolute concentration index explain why the values for the absolute concentration index are smaller than those for the regular concentration index. Fourth, as with relative inequality, it appears that the upward drift in the intervention markers over time has been associated with less absolute inequality, whereas for the malnutrition and mortality indicators, the pattern is less clear. Fifth, as with relative inequality, we still see evidence of inequalities even in the latest data.

Figure 6 shows the global distribution, for each indicator, of annual average changes in the standard and absolute concentration indices; see also columns 7, 8, 9, 11, 12 and 13 of table 5. Two points are worth highlighting.

First, reductions in relative inequality are more evident for the intervention indicators than for the health status indicators. For IMR, roughly half of countries saw relative inequality increase, and half saw it fall. For the other four health status indicators, only a slight majority of countries saw a reduction in relative inequality, and the (absolute) percentage change per year in relative inequality was small (typically less than one percent). The health status indicator that bucks this trend is HIV prevalence, where 67 percent of countries saw relative inequality fall and the regular concentration index fell by 2.3 percent per year. Keep in mind, however, that in the initial round of surveys, HIV was more prevalent among the better off, not the poor. Thus, although a reduction in inequality occurred, it was not a pro-poor change. On the intervention indicators, reductions in inequality are more pronounced. On average, nearly three-quarters of countries record reductions in relative inequality on the intervention indicators, and the annual reduction in the concentration index averages approximately four percent. 

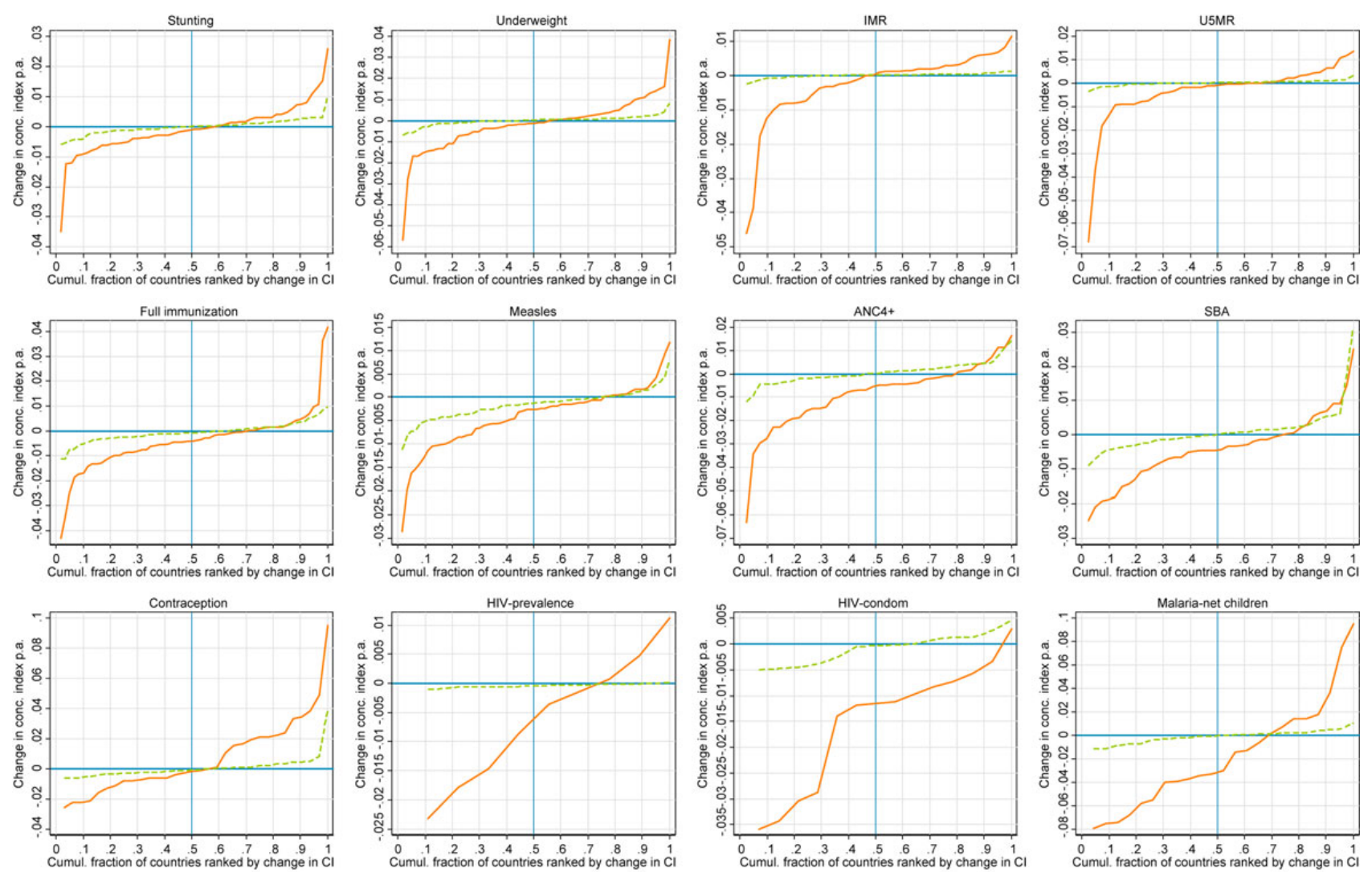

Concentration index

---- Absolute concentration index

Notes: The vertical axis measures the annual average change in the index, not the percentage change. 
Second, fewer countries have experienced reductions in absolute inequality than relative inequality and the median reductions in absolute inequality are smaller. On the malnutrition and child mortality indicators, we actually see increases in absolute inequality in the majority of countries, with changes in the absolute concentration index for these indicators averaging three percent. On the intervention indicators, we see reductions in absolute inequality, but the percentage reductions in absolute inequality are, on average, half as large as the percentage reductions in relative inequality. The different behaviors of the relative and absolute inequality measures reflect the fact that an improvement for someone in the richest half of the population will cause absolute inequality to rise, but it need not cause relative inequality to rise. Depending on the initial concentration index value, improvements for people well above the mid-point of the wealth distribution could still be compatible with a reduction in relative inequality. ${ }^{11}$

\section{Discussion}

The developing world as a whole is making progress toward all MDG indicators. Unsurprisingly, perhaps, given the different starting points, progress has been slower on some indicators (for example, immunization, which had higher initial rates of coverage) than on others (for example, antenatal care coverage, which had lower initial rates). More surprising is the fact that for every indicator, there are several countries that have gone backwards. For some indicators, the fraction of such countries is quite high: one-quarter for immunization and one-fifth and onethird for underweight and stunting.

The main focus of this paper, however, has been on differential progress between the poor and the better off. There are three key messages of this paper. First, in a majority of countries, the poorest 40 percent are making faster progress than the richest 60 percent, and, on average, relative inequality in the MDG indicators has been falling. Second, in an appreciable fraction of countries, the poorest 40 percent have not been progressing in absolute terms. Moreover, in a sizable fraction of countries, the poorest 40 percent have progressed less quickly than the richest 60 percent, and relative inequality has been growing. This is especially true of the child health status indicators (for child malnutrition and mortality, the fraction in this latter category is 40 to 50 percent), but it is also true of some intervention indicators (for immunization, the figure is almost 40 percent). Third, although, on average, relative inequality has been falling, appreciable inequalities remain. In the latest round of surveys used in this study (of which all but two are from the 2000s) and based on a comparison of odds ratios, the richest 60 percent of children in the developing world are 1.2 times as likely to sleep under a bednet, 1.5 times as likely 
to be immunized, and 3.7 times as likely to have been delivered by a skilled birth attendant as the poorest 40 percent of children.

On the subset of issues that we address and that previous authors have addressed, we see some similarities in results as well as some differences. Our results are broadly consistent with those of Victora et al. (2012) and Suzuki et al. (2012) who found pro-poor progress on most of the MDG intervention indicators that were also examined here; the exception is SBA, which Suzuki et al. (2012) concluded had been pro-rich. On inequalities in health status indicators, our results on under-five mortality are consistent with those of Moser et al. (2005), who found that progress had been neither pro-poor nor pro-rich on balance. However, our results on underweight are less encouraging than those of Suzuki et al. (2012), who found pro-poor progress in more than 60 percent of countries. Differences in findings may be due to variations in the methodological approaches adopted, such as differences in the number of countries included, time period examined, the definition of poor and non-poor and the measure of inequality.

Our first finding - that in most countries the poor have not been left behind by the health MDGs - will be reassuring to donors, international development and technical agencies, national governments, NGOs, program implementers, and health care professionals. However, our other two findings - that relative inequalities have grown in a sizable minority of countries, especially on health status indicators, and that despite reductions in most countries, inequalities are still appreciable - will be a cause for concern. Governments, donors and NGOs ought to be able to exert a fairly direct influence over the coverage of immunization, skilled birth attendants, and bednets, among others. Our findings suggest that Gwatkin (2005) was right to warn that programs that improve population averages may not necessarily disproportionately benefit the poor. In addition, they imply that it is indeed important to monitor progress not only on population averages but also on inequalities - a point made by the UN's 2013 high-level panel report on the post-2015 development agenda (United Nations 2013). Our results should prompt further discussion of appropriate policies to reduce inequalities in intervention coverage and health status. For example, are universalist policies the answer, or is there a greater need for targeting efforts toward the poor? Do 'new' initiatives such as conditional cash transfers and pay-for-performance stand a better chance of reducing inequalities than 'traditional' approaches such as pure input-financing?

Our finding that progress on interventions has been considerably more pro-poor than progress on health status is a puzzle that merits further research. One hypothesis is that the quality of health care is worse for lower socioeconomic groups; though the poorest 40 percent may have experienced a larger percentage increase in, for example, antenatal visits, they have not observed the same improvement in the survival prospects of their babies. If true, this finding would point to the need for a monitoring framework that captures not only the quantity of care (as is 
currently the case) but also its quality. Another hypothesis is that although inequalities in the official monitoring indicators have been narrowing, inequalities in at least some of the interventions that are not monitored may have been widening. Obvious examples are health interventions delivered privately (i.e., in the home) by caregivers, which are often complementary to monitored interventions, such as breastfeeding, hand-washing, and antibiotics for a child suffering from dysentery or pneumonia. These are indicators that a UN technical consultation suggested should be tracked but that did not obtain official indicator status. As a result, the interventions in question may have been under-promoted. If this is the case, it may suggest the need for a broadening of the monitoring framework to capture interventions delivered by caregivers as well as a policy shift in the health sector toward preventive and curative interventions delivered in the home and in the community.

\section{Notes}

Adam Wagstaff: Development Research Group, The World Bank, 1818 H Street, NW, Washington, DC 20433, USA; Caryn Bredenkamp: Health, Nutrition and Population Global Practice, The World Bank, 1818 H Street, NW, Washington, DC 20433, USA; Leander R. Buisman: Institute of Health Policy and Management, Erasmus University Rotterdam, PO Box 1738, 3000 DR Rotterdam, The Netherlands. Corresponding author: Adam Wagstaff. Development Research Group, The World Bank, $1818 \mathrm{H}$ Street, NW, Washington, DC 20433, USA. Tel: +1 202473 0566, awagstaff@worldbank.org). The research reported in this paper was supported by the World Bank's Rapid Social Response Multi-Donor Trust Fund (RSR-MDTF). We are grateful to Nicole Klingen, Gayle Martin, Owen Smith, Aparnaa Somanathan, Owen O'Donnell, Ellen Van de Poel, Jos Verbeek, Xiaoqing Yu, the WBRO editor, and three anonymous referees for advice and useful comments on earlier versions of the paper. The findings, interpretations and conclusions expressed in this paper are entirely those of the authors and do not necessarily represent the views of the World Bank, its Executive Directors, or the governments of the countries they represent.

1. Throughout this paper, "pro-poor" indicates that changes in MDG health indicators are such that there is a reduction in inequality (in the indicator) between the poor and better-off. This is in the spirit of the definition of pro-poor growth proposed by Kakwani and Pernia (2000) (i.e. growth that reduces income inequality) and the definition of pro-poorness used in the context of the redistributive effects of taxes and transfers (i.e. taxes and transfers that reduce income inequality) (Lambert 2001).

2. Some official indicators, such as the number of tuberculosis (TB) cases detected and treated under DOTS, cannot be constructed from the DHS or MICS. Deaths from malaria and TB are also not captured by regular household surveys such as the DHS and MICs, partly because of sample size issues but also because of the difficulty of ascertaining after the fact the cause of death. Maternal mortality is often computed using variables from the DHS, but maternal deaths are so rare that quintile-level analysis would not be meaningful.

3. The official indicator captures only measles immunization.

4. We include two additional MDG6 indicators: condom use and HIV prevalence.

5. The wealth index is created by using principal components analysis to construct a weighted average of a variety of indicators capturing the ownership of assets (e.g., car and television) and the characteristics of the family's home (e.g., type of floor and roof). Subsequent to the work of Gwatkin et al. (2000; 2007), who published tabulations by 'wealth quintile' of a large battery of health, 
nutrition and population indicators for all DHS surveys, the organization responsible for the DHS (then Macro International) decided to include the Filmer-Pritchett wealth index in each public-release DHS dataset. UNICEF, which is responsible for the MICS, subsequently decided to do the same with the MICS.

6. The poorest 40 percent is the target group in the World Bank Group's (WBG) new goal of 'promoting shared prosperity'; see, e.g., http://www.worldbank.org/content/dam/Worldbank/document/ WB-goals2013.pdf, where the WBG states, "We will monitor progress in shared prosperity using the income growth of the bottom 40 percent of a nation's population. This implies a direct focus on the income of the less well-off, as opposed to the common practice of focusing only on growth of GDP per capita and implicitly relying on the "trickle down" impact of growth on the bottom of the distribution. The measure captures the two elements central to the notion of shared prosperity: a growing economy and a fundamental concern for equity."

7. Growth rates are computed using information from all available survey years. We assume a compound growth process and estimate the average annual percentage change by regressing - for each country and each indicator, separately for the population and the poorest 40 percent - the natural logarithm of the indicator on the date of the survey. The average annual rate of growth is equal to the exponential of the (regression) coefficient on the year variable minus one (see, e.g., http://data.worldbank.org/about/data-overview/methodologies).

8. Concentration indices were computed from the individual-level data, not the quintile data, using the convenient covariance method (see, e.g., Jenkins 1988), except in the case of the mortality variables, whose concentration indices were computed from quintile data (see, e.g., Kakwani et al. 1997).

9. The absolute concentration index is the same as the generalized concentration index. The former is derived from the absolute concentration curve and the latter from the generalized concentration curve. On absolute inequality, see Jenkins and Jäntti (2005 p.14), Moyes (1987 p.205) and Lambert (2001 p.56). In the health context, see Wagstaff et al. (1991) and Wagstaff (2009).

10. This follows from the fact that the absolute concentration index is equal to the mean times the standard concentration index.

11. Wagstaff (2009) proves both results. An increase in individual i's outcome (holding everyone else's constant) will raise absolute inequality if person $i$ is in the upper half of the wealth distribution. The same increase will raise relative inequality only if the person's rank in the wealth distribution exceeds $1 / 2(\mathrm{CI}+1)$, where $\mathrm{CI}$ is the value of the (initial) concentration index. Therefore, if $\mathrm{CI}$ is 0.25 , person i's rank in the wealth distribution would have to be above 0.625 for relative inequality to increase.

\section{References}

Deaton, A. 1997. The Analysis of Household Surveys: A Microeconometric Approach to Development Policy. Baltimore, MD: Johns Hopkins University Press.

Filmer, D., and L. Pritchett. 2001. "Estimating wealth effects without expenditure data or tears: An application to educational enrollments in states of India." Demography 38 (1) : 115-32.

Go, D. S., and J. A. Quijada. 2012. "The Odds of Achieving the MDGs." The World Bank Research Observer 27 (2) : 143-84.

Gwatkin, D., S. Rutstein, K. Johnson, R. Pande, and A. Wagstaff. 2000. Socioeconomic Differences in Health, Nutrition and Population. Washington, DC: The World Bank.

Gwatkin, D., S. Rutstein, K. Johnson, E. Suliman, A. Wagstaff, and A. Amouzou. 2007. Socio-Economic Differences in Health, Nutrition and Population Within Developing Countries: An Overview. Washington, DC: The World Bank. 
Gwatkin, D. R. 2005. "How much would poor people gain from faster progress towards the Millennium Development Goals for health?” The Lancet 365 (9461) : 813-17.

Jenkins, S. 1988. "Calculating income distribution indices from microdata." National Tax Journal 61 : $139-42$.

Jenkins, S. P., and M. Jäntti. 2005. "Methods for summarizing and comparing wealth distributions." Working Paper, Colchester, University of Essex, Institute for Social and Economic Research.

Kakwani, N., and E. M. Pernia. 2000. "What Is Pro-poor Growth?” Asian Development Review 18 (1) : $1-16$.

Kakwani, N., A. Wagstaff, and E. van Doorslaer. 1997. "Socioeconomic Inequalities in Health: Measurement, Computation, and Statistical Inference." Journal of Econometrics 77 (1) : 87-103.

Lambert, P. 2001. The distribution and redistribution of income: A mathematical analysis. Manchester: Manchester University Press.

Moser, K. A., D. A. Leon, and D. R. Gwatkin. 2005. "How does progress towards the child mortality millennium development goal affect inequalities between the poorest and least poor? Analysis of Demographic and Health Survey data." BMJ 331 (7526) : 1180-2.

Moyes, P. 1987. “A new concept of Lorenz domination.” Economics Letters $23: 203-7$.

Suzuki, E., M. Sharan, and E. Bos. 2012. Poverty and Health Monitoring Report. Washington, DC: World Bank.

United Nations. 2012. Millennium Development Goals Report, 2012. New York: United Nations.

2013. A new global partnership: eradicate poverty and transform economies through sustainable development. The report of the high-level panel of eminent persons on the post-2015 development agenda. New York: United Nations.

Victora, C. G., A. J. D. Barros, H. Axelson, Z. A. Bhutta, M. Chopra, G. V. A. França, and K. Kerberet al. 2012. "How changes in coverage affect equity in maternal and child health interventions in 35 Countdown to 2015 countries: an analysis of national surveys." The Lancet 380 (9848) : $1149-56$.

Wagstaff, A. 2005. "The bounds of the concentration index when the variable of interest is binary, with an application to immunization inequality." Health Economics 14 (4) : 429-32. 2009. "Correcting the concentration index: A comment." Journal of Health Economics 28 (2) : 516-20.

Wagstaff, A., C. Bredenkamp, and L. R. Buisman. 2014. "Progress Toward the Health MDGs: Are the Poor Being Left Behind?” Policy Research Working Paper 6894, World Bank, Washington, DC.

Wagstaff, A., and M. Claeson. 2004. The Millennium Development Goals For Health: Rising to the Challenges. Washington, DC: World Bank.

Wagstaff, A., P. Paci, and E. van Doorslaer. 1991. "On the measurement of inequalities in health." Social Science \& Medicine 33 (5) : 545-57.

World Bank. 2013. Global Monitoring Report 2013: Rural-Urban Dynamics and the Millennium Development Goals. Washington, DC: World Bank. 